\title{
Virtual World Users Evaluated According to Environment Design, Task Based and Affective Attention Measures
}

\author{
Breen Sweeney and Anne Adams \\ The Open University \\ bs239@tutor.open.ac.uk, a.adams@open.ac.uk
}

\begin{abstract}
This paper presents research that engages with virtual worlds for education users to understand design of these applications for their needs. An in-depth multi-method investigation from 12 virtual worlds participants was undertaken in three stages; initially a small scale within-subjects eye-tracking comparison was made between the role playing game 'RuneScape' and the virtual social world 'Second Life', secondly an in-depth evaluation of eye-tracking data for Second Life tasks (i.e. avatar, object and world based) was conducted, finally a qualitative evaluation of Second Life tutorials in comparative $3 \mathrm{D}$ situations (i.e. environments that are; realistic to surreal, enclosed to open, formal to informal) was conducted. Initial findings identified increased users attention within comparable gaming and social world interactions. Further analysis identified that 3D world focused interactions increased participants' attention more than object and avatar tasks. Finally different 3D situation designs altered levels of task engagement and distraction through perceptions of comfort, fun and fear. Ultimately goal based and environment interaction tasks can increase attention and potentially immersion. However, affective perceptions of $3 \mathrm{D}$ situations can negatively impact on attention. An objective discussion of the limitations and benefits of virtual world immersion for student learning is presented.
\end{abstract}

\section{Categories and Subject Descriptors}

H.1.2 [User/Machine Systems] Human factors; H.5.2 [User Interfaces] Ergonomics, Evaluation/methodology, User-centered design.

\section{General Terms}

Design, Experimentation, Human Factors

\section{Keywords}

Social worlds, Gaming, Attention, Immersion, MUVE, MMORPG.

\section{INTRODUCTION}

\subsection{Background}

It is important to understand how students engage with different technologies for learning purposes to assess their limitations and value. Virtual reality is a relatively old technology, yet it is only recently that web-based gaming and social worlds have captured the imagination of educationalists on a large scale. It is important to understand that the technology itself does not possess solutions for education. However, an understanding of the how this technology supports end-user engagement might support learning environment design for virtual worlds.

Virtual reality is a computer-based application which allows human-computer and human-human interactivity through a sensory environment called the virtual world which is dynamically controlled by the user's actions. Virtual environments rely heavily on the notion of immersion both physically and cognitively. The increased use of tactile input devices for games (e.g. data gloves, Wii fit board) may increase physical immersion. However, a user is cognitively immersed in the environment when they feel immersed in the interaction $[18$, 7, 3].

Initially virtual environments were used for entertainment and training purposes. Virtual simulations of complex real world systems have been used as learning environments for various conditions $[16,6]$. However, the objectives of virtual reality have digressed into three main themes [7]:

1) The user's exploration of the virtual world.

2) The user's actions on the real world through virtual replications (simulations)

3) The user's interaction with other users' participating in the virtual world.

This paper and the studies detailed concentrate primarily on scenario 1 which relates to the concept of virtual world exploration. However even if we are not interacting with others psychologically we have built into us the concept of acceptable behaviours for appropriate places. For example, even if we we are alone in a traditionally public space (e.g. a supermarket) we would feel uncomfortable completing a private act (e.g. taking off our clothes in this context). This is an example of social norms guiding our behaviours for 'places' irrespective of our current social interactions. Social norms (such as politeness and acceptable behaviour) guide social interactions and determine socially rich responses irrespective of whether a system was designed to cater for them $[13,15]$. Based on existing knowledge, users construct social representations that allow 


\section{B. Sweeney et al}

them to recognize and contextualize social stimuli. These representations originate from social interaction and help us construct an understanding of the social world, enabling interaction between groups sharing the representations: social norms [1]. Social situations provide cues that allow people to make assessments of those situations. Harrison \& Dourish [9] argue that it is a sense of place that guides social interactions. This is because social norms guide our perceptions of spaces allowing us to interpret them as places and adapt our behaviours accordingly. Virtual worlds have long been understood to allow end-users an increased sense of place for interactions. However, there is still more to be understood about how this impacts on our interactions with inaccurate assumptions about the world and how much we feel a part of this world or are 'immersed' in it.

The terms 'immersion' and 'immersiveness' are used to describe the degree of involvement in a virtual world, and the terms are usually applied to games. Although their meaning is intuitively understood by participants in those worlds, Brown and Cairns [3] highlight that there is not a currently agreed definition of the terms. In their paper they attempt to develop a grounded theory analysis of immersion, based on interviewing gamers to learn about their experiences. Other attempts have been made to quantify immersion using specific tasks, or eye tracking techniques [3,5]. However, how these relate to learning attention for different environmental goals (e.g. gaming as opposed to social interaction), tasks, self and situational interactions are still to be fully understood and are the focus of this paper

\subsection{Virtual Worlds in Education}

Collaborative virtual environments provide remotely located users with the ability to collaborate via real interactions in a shared artificial environment [2]. The advantages of virtual reality for collaborative learning are frequently argued by constructivists $^{1}$ to relate to the importance of authentic context [19]. Virtual reality (VR) communication environments have been argued to provide a natural, intuitive environment for communication whilst releasing some of the social taboos from social interactions [11]. However as virtual worlds increase in their appearance as accurate replications of reality there is an increased likelihood that users will make inaccurate assumptions about the world's capabilities and limitations. This could have inappropriate impacts on end-users task attention and ultimately immersion in the environment and task. For example, a realistic classroom could produce user assumptions that the environments walls and doors retain real world characteristics, thus implicitly making conversations within a VR room appear private when they may actually be public.

One learning theory suggests that the student goes through an experiential cycle where abstract concepts and generalisations are formed, these are tested in new situations, which leads to concrete experiences, followed by observations and reflections, beginning the cycle again with a new formation stage [12]. Adopting this as our model, when students attend a tutorial it will be expected that they will participate in some of these

\footnotetext{
1 Constructivism is a predominant psychological process theory in collaborative learning. They highlight the importance of learning environment actions, real interactions and translating abstract concepts into those that are concrete. For further information see Vygotsky [19].
}

stages. Therefore anything that helps the student focus their attention will aid in the process, whereas conversely anything that distracts the student will hinder them. It could be argued therefore, that immersion is a key aspect of a learning cycle.

There has been a great deal of research on reviewing educational virtual worlds and learning within other online environments. Over 15 years of virtual reality / world research has reviewed the learning and training aspects of these environments [16]. Tisdell et al. [17] discuss a broad literature around online learning, before going on to describe their own action research on student cohorts. Current research has focused on specific aspects of learning within virtual worlds. Delwiche [6] used the game Everquest and also Second Life to teach research methods, game design and cyber culture. However, the educational community is deeply divided as to the benefits and limitations of designing virtual worlds as a place for learning. Some educationalists are sceptical about using virtual worlds for learning [8]. Others however are enthusiastic, and feel it is possible to achieve ambitious educational goals [14]

\subsection{Studies Aim}

Eye tracking hardware can determine where a user is gazing at any time and hence record eye movements. When this is used to test immersion the usual approach is to see if the nature of the eye movements are altered as a user becomes more immersed [4]. This paper reviews an alternate use of eye tracking techniques. As a user progresses through a virtual world they are presented with a range of stimuli, and will look at various parts of the screen. The hypothesis being used in this paper is that the more immersed a user is, the more they will have an increased attention on their own avatar, rather than look at other areas of the screen. This is because they will be more interested in what their own avatar is doing, and identify with it, rather than looking at other activities or objects in the surrounding area. It is argued that this will give them a sense of presence in the place. This paper seeks to review this concept of "virtual self attention' when other variables are impacting on end-users learning focused interactions. Initially the importance of focus within different environments, retaining different goals (e.g. gaming and social interaction) and finally on attention and immersion levels are investigated. At a second stage of analysis the impact on participants' attention and thus immersion levels when interacting with tasks, concepts of self and with the world around us are examined. At a final stage of analysis we look at how affective interpretations of the virtual world around participants impact on their ability to focus on learning tasks such as tutorials.

Ultimately this paper also examines Second Life impacts on student learning, and considers what lessons we can learn when designing teaching environments.

\section{Attention studies}

\subsection{Environments interactions}

An initial study was conducted to evaluate the impact of environmental interactions (i.e. social world compared to gaming) on end-users attention and thus immersion levels. Initially a small scale within-subjects eye-tracking comparison was made between the role playing game RuneScape and the 
virtual social world Second Life. RuneScape is a Java-based massively multiplayer online role-playing game owned by Jagex Ltd., which has a business model that offers a free, browser based game partly funded by advertising, but also offers a membership option where players can pay to access more features. Second Life is a $3 \mathrm{D}$ virtual world owned by Linden Labs which offers a free basic account, but also offers premium paid-for accounts which have additional benefits. It is a social world rather than a game in that there are no stated aims or tasks. However, although people do develop games within Second Life, nearly every object in the game is built by the endusers.

For the environment comparisons a Tobii T60 eye tracking monitor was connected to a purpose-built computer running Windows. Initially a calibration exercise was used with the system tracking the user sitting and controlling the avatar. The Second Life screen was divided into the top controls, the bottom controls, and the game window. The game window was further divided into a top and bottom region, and a left, central and right region. The RuneScape screen was similarly divided into the top browser controls and advertisements region, the bottom controls, and top, bottom, left, middle and right sections of the game window.

A comparison was made between Second Life and RuneScape, to see if there were any attentional differences observed, as a first step towards quantifying whether users became more immersed in a game or in a social virtual world. It was also considered whether the average fixation duration might differ between these virtual worlds.

As previously noted it is suggested that as users become more immersed they may concentrate on their avatar and ignore other elements of the virtual world around them. To test the hypothesis, and to make comparisons between Second Life and the game RuneScape, a pilot study was carried out with six university staff members. All were women who were unfamiliar with either of the worlds, although participant number five had played other role playing games.

A female Second Life avatar was created for the experiment. To comply with RuneScape regulations and to ensure each person had the same starting point in the game, individual RuneScape avatars were created and brought through the game's orientation tutorial, and placed in the same position in the game world. This was important because in a role playing game as a player progresses their avatar's characteristics change. Each participant was then asked to $\log$ into Second Life and carry out a number of standard tasks. After a break the participants then carried out comparative standard tasks in RuneScape. The sessions lasted about thirty minutes per world.

\subsubsection{Details of the Tasks Undertaken}

The tests were designed to increase initial task engagement and immersion to allow for standardized comparisons between general world engagement as opposed to initial encounters and interactions with obstacles. To increase naturalistic yet focused interactions the instructions were spoken aloud and participants were free to ask for help if they didn't understand anything. Each participant was allowed to carry out slightly different activities, whilst the verbal instructions ensured a level of standardization between participants' tasks thus increasing naturalistic yet standardized tasks.

Within Second Life the participants were asked to engage with their avatar, carry out navigation tasks, change their avatar appearance, randomly teleport and navigate without instructions, and build objects. Within RuneScape the participants were asked to engage with their avatar, navigate (i.e. using walking, running and exploring as well as using teleport), find and bury bones, then fight with a monster, play a church organ, carrying out fishing activity, do the initial stages of a quest, deposit items in a bank then finally chop down and burn trees. The number of tasks reflects the task-based nature of the role-playing game, where each task may be done in a short time. For those participants who progressed quickly, optional additional tasks of finding monsters and killing them via archery were added.

In both worlds the participants carried out initial "calibration steps', to get them used to the controls, and these were then excluded from the analysis, thus ensuring the initial time spent logging in and learning about the controls had a minimal effect on the study.

\subsubsection{Results}

With the eye-tracking analysis it is important to understand that when the eye's gaze moves across the screen this is known as a saccade, and the person is effectively blind during this movement [10]. Although the position of the eye's gaze changes fractionally all the time, when the gaze has been in the same area for some time, this is called a fixation. Hence a longer average fixation time (or equivalently a fewer number of fixations in a minute) means the eyes were focussed on fewer points on the screen, whereas a shorter time means the eyes were moving about and observing more parts of the screen.

It must be noted that the eye tracking was an in-depth pilot study, thus it only contained a few individuals. Difficulties in determining the exact position of the controls could have resulted in a small amount of time attributed to game window focus that had been spent on looking at the controls. However as the figure we are looking for is time spent in the centre this would not affect the overall conclusions.

Descriptive percentages identified that the fixations in Second Life were longer than in RuneScape for four participants, although for two participants the findings were directly reversed. However, overall averages were very similar (see table 1). This data is therefore inconclusive and isn't discussed further in this paper.

Table 1: Comparison of Fixation Duration

\begin{tabular}{|l|l|l|}
\hline \multirow{2}{*}{} & \multicolumn{2}{|c|}{ Average fixation duration (seconds) } \\
\cline { 2 - 3 } & \multicolumn{1}{|c|}{ Second Life } & \multicolumn{1}{c|}{ RuneScape } \\
\hline Participant 1 & 0.3853880661 & 0.3661889843 \\
\hline Participant 2 & 0.3088540512 & 0.2881853435 \\
\hline Participant 3 & 0.4757050118 & 0.4554075305 \\
\hline Participant 4 & 0.2382597320 & 0.3810752630 \\
\hline Participant 5 & 0.5068433515 & 0.4191527130 \\
\hline Participant 6 & 0.2188112158 & 0.2421717268 \\
\hline Overall & 0.355643571 & 0.358696944 \\
\hline
\end{tabular}


The data was then analysed to identify the percentage times spent in various areas of the screen (see tables 2, 3).

Table 2: Percentage time spent in screen areas

\begin{tabular}{|l|l|l|}
\hline \multirow{2}{*}{$\begin{array}{l}\text { Gaze not } \\
\text { captured }\end{array}$} & 17.54832825 & RuneScape \\
\hline $\begin{array}{l}\text { Looking at top } \\
\text { controls } \\
\text { (Second Life) } \\
\text { / }\end{array}$ & 1.145668877 & 2.27215494 \\
$\begin{array}{l}\text { Browser/Ads } \\
\text { (RuneScape) }\end{array}$ & 11.14461636 & 10.49035438 \\
\hline $\begin{array}{l}\text { Top of game } \\
\text { window }\end{array}$ & 7.718010652 \\
\hline $\begin{array}{l}\text { Left part of } \\
\text { game window }\end{array}$ & 5.649756166 & 40.69165337 \\
\hline $\begin{array}{l}\text { Central part of } \\
\text { game window }\end{array}$ & 34.38094236 & 10.68237491 \\
\hline $\begin{array}{l}\text { Right part of } \\
\text { game window }\end{array}$ & 11.19496193 & 6.22871314 \\
\hline $\begin{array}{l}\text { Bottom of } \\
\text { game window }\end{array}$ & 15.60835702 & 0.870164147 \\
\hline $\begin{array}{l}\text { Looking at } \\
\text { bottom } \\
\text { controls }\end{array}$ & 3.327369049 & \\
\hline
\end{tabular}

Table 3: Percentage time spent in game window

\begin{tabular}{|c|c|c|}
\hline & Second Life & RuneScape \\
\hline $\begin{array}{l}\text { Top of game } \\
\text { window }\end{array}$ & 14.2918846 & 13.83749015 \\
\hline $\begin{array}{l}\text { Left part of } \\
\text { game window }\end{array}$ & 7.245261796 & 10.18058041 \\
\hline $\begin{array}{l}\text { Central part of } \\
\text { game window }\end{array}$ & 44.09020865 & 53.67505538 \\
\hline $\begin{array}{l}\text { Right part of } \\
\text { game window }\end{array}$ & 14.35644789 & 14.09077826 \\
\hline $\begin{array}{l}\text { Bottom of } \\
\text { game window }\end{array}$ & 20.01619706 & 8.216095809 \\
\hline
\end{tabular}

In RuneScape the avatar is in the centre of the game window, and under normal circumstances this is the same situation for Second Life. Hence it is to be expected that the participants gaze would be in this area more than twenty percent of the time. Nevertheless the validity of the experiment depends only on a comparison between the worlds. In fig. 1 we can see the time spent in the central area as a percentage of the game window, which was $44 \%$ for Second Life and $56 \%$ for RuneScape to the nearest integer. These initial findings highlight an increased level of end-user focus within gaming world compared to social world interactions.

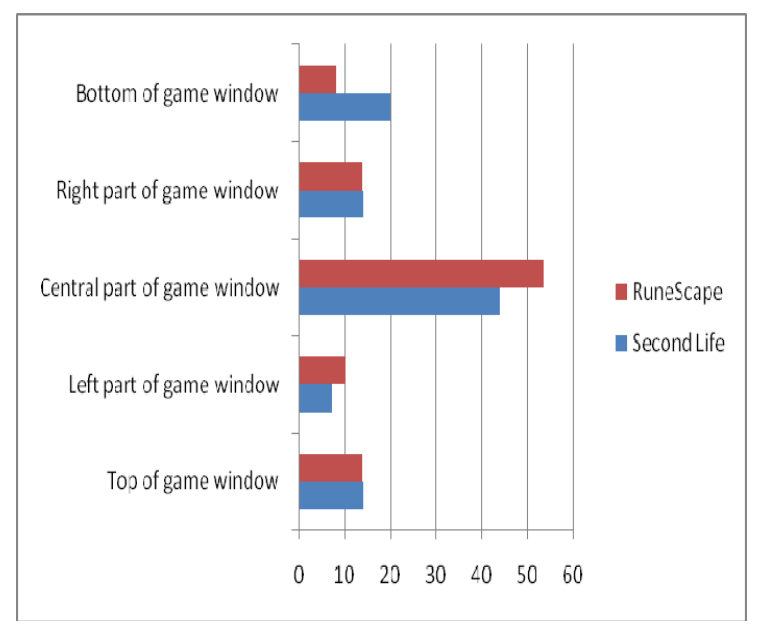

Figure 1 - percentage of attentional focus for Second Life and RuneScape

\subsection{Task-Based interactions}

The data obtained from Second Life was further analysed. The tasks the participants had engaged in were divided into three types. 'World' tasks consisted of activities where participants were dealing with the general environment, for example navigating to various places. 'Avatar' tasks were those where participants were concerned with their own avatar, such as changing their Second Life appearance. 'Object' tasks were the activities which had participants doing things with objects inworld, such as for example carrying out building tasks.

\subsubsection{Results}

For the Second Life data the time spent looking at the central part of the screen was analysed for each of the separate tasks. The research aim was to see if the participants were more or less immersed during the different types of activities. Table 4 shows a summary of this analysis.

Table 4: Percentage of time spent focused on central areas for each task.

\begin{tabular}{|l|l|l|l|}
\hline & \multicolumn{3}{|c|}{ Tasks } \\
\cline { 2 - 4 } & Avatar & World & Object \\
\hline $\begin{array}{l}\text { Part. } \\
1\end{array}$ & 37.10935024 & 49.32545291 & 44.57970642 \\
\hline $\begin{array}{l}\text { Part. } \\
2\end{array}$ & 46.94356285 & 46.03777122 & 42.65648606 \\
\hline $\begin{array}{l}\text { Part. } \\
3\end{array}$ & 37.15060649 & 49.51836843 & 64.22247725 \\
\hline $\begin{array}{l}\text { Part. } \\
4\end{array}$ & 37.70727249 & 60.19165178 & 43.10564277 \\
\hline $\begin{array}{l}\text { Part. } \\
5\end{array}$ & 36.37665593 & 54.70420392 & 41.81088538 \\
\hline $\begin{array}{l}\text { Part. } \\
6\end{array}$ & 27.23970944 & 40.95888645 & 32.74282838 \\
\hline $\begin{array}{l}\text { Ave } \\
\text { rage }\end{array}$ & 37.08785957 & 50.12272245 & 44.85300438 \\
\hline
\end{tabular}


The average percentage time spent in the central region (to the nearest integer) was $37 \%$ for avatar tasks, $50 \%$ for world tasks, and $45 \%$ for object tasks (see figure 2 ). This data clearly shows there is more concentration on the central part of the screen during tasks related to the general world, such as navigation.

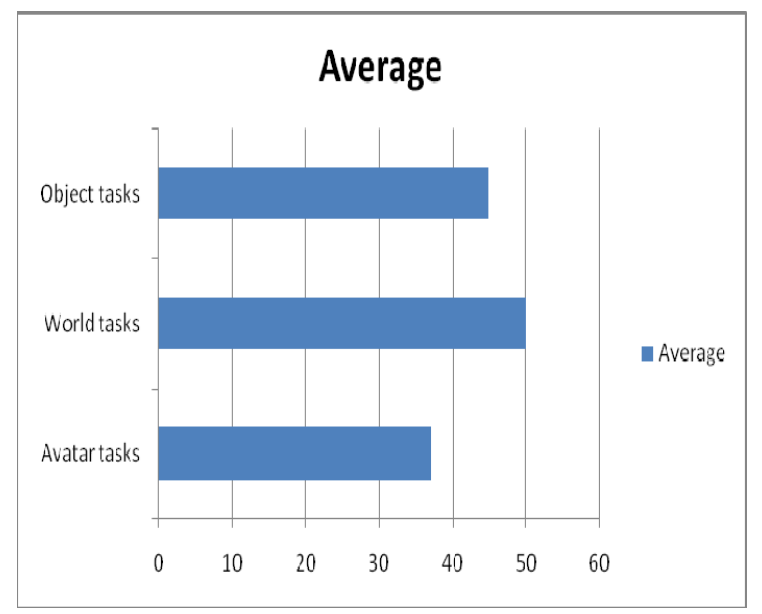

Figure 2 - Average percentage by tasks in Second Life

\subsection{Virtual Tutorials}

\subsubsection{Situational Affective Measures}

A further six participants attended a series of virtual world tutorials. The participants were students studying a 2008 second-level course in Pure Mathematics. The course covers introductory material, linear algebra, group theory and real analysis. Tutorials took place on the Second Life islands of SchomeBase and Open Life. The in-world voice facilities were used, and conversations were controlled via turn-taking. The students could use text-chat to ask questions or say when they wanted to speak.

Three orientation meetings were held (see figure 3), followed by seven mathematics tutorials. The initial sessions were deemed essential to allow students to overcome technical problems and learn about the environment. Written material was circulated beforehand and then discussed during the tutorials.

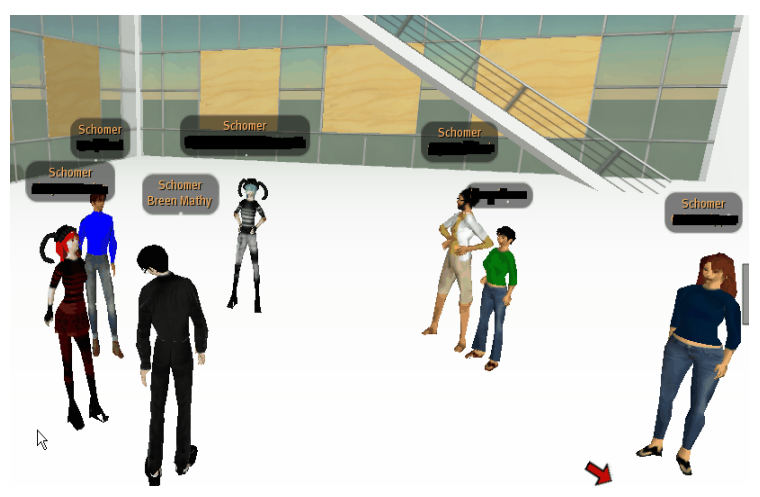

Figure 3 -Participants attending an orientation meeting
To investigate how the situational setting affected education within the tutorials a variety of different situational settings were used for the tutorials. These were devised according to three separate factors; realistic to surreal, enclosed to open, formal to informal (see figure 4). The specific situations used were: two different platforms in trees, one which had couchlike seats, a purpose-built enclosed classroom and corridor in the sky, the same room with the roof removed, a purpose-built chessboard room with wall and chairs, and a bandstand.

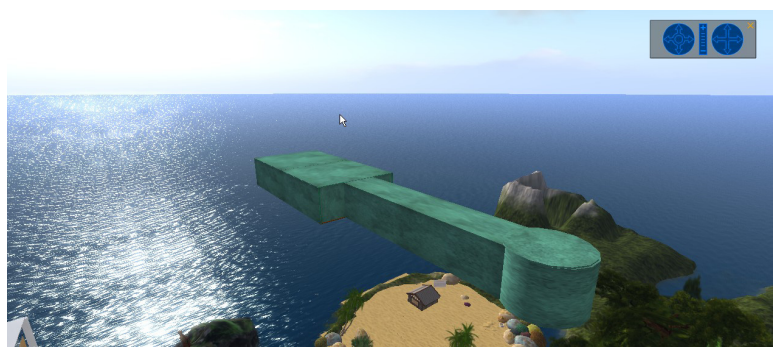

Figure 4 - Enclosed location used for tutorials

A forum was set up on the universities intranet, and agendas and minutes of each session were posted for the students and interested staff to view. A personal log was kept of comments made and lessons learned, in particular with relation to the practical and technical aspects of teaching in Second Life. Three students not currently on the course sat in on some sessions, but were not included in the analysis.

Five of the students then took part in telephone interviews. The questions for the interviews were focused around four themes: participant perceptions of motivation, task interactions, input / output devices and 3D situations. This qualitative data was transcribed and thematically analysed.

\subsubsection{Students' Attention and Learning}

The analysis of the students' responses showed concurrent themes although slight discrepancies were identified. All agreed that Second Life had advantages similar to other online learning mediums. The students agreed that it is a very efficient way to learn and the social aspects of the environment were considered in a positive light.

During the tutorials many critical issues also arose e.g. the extent to which the students were really engaged with the tutorial. The fact that no face-to-face contact was taking place (e.g. no eye-contact), combined with the fact that students were using prepared material in addition to the voice contact, would raise questions about the degree of student immersion in general. However investigating those issues further would involve a separate study, comparing real life tutorials with virtual ones. This paper concentrates on social world immersion issues from the students. The focus on immersion highlighted issues of attention and the question of how the different environments affected the learning. 


\subsubsection{Social World Environment Results}

Ultimately the different 3D situation designs presented to the participants altered levels of task engagement and distraction through perceptions of comfort, fun and fear.

When the students were asked about the different environments, in general their opinion was that the differences didn't have a great effect. However their specific comments suggested otherwise. There were issues of affective memories triggered by environments that impacted on end-user perceptions.

'I quite liked the tree house. ...Silly reason for that is that going back to primary school it's quite nice sitting outside doing various things, and it kind of reminded me of that, and I thought this is kind of fun, it's good. ... The one with the roof open was quite interesting. As you said last night at that time as well we went through a complete day, where we had the dawn and then watched the evening and the stars came out. ... Yeah, it just reminded me of a sort of bar outside of a hotel you know where you sit in an evening. That was OK actually, but there is something about somebody sort of standing around who you're not quite sure who they are, 'Oh, who are they then?' (Student 1)

Significantly however none of the students likes the classroom with the roof on, because it was closed and had no windows. Two did admit to being mildly claustrophobic in real life.

I think the only one that I actually disliked was the M208 classroom with the roof on. It just felt very weird, it was like going down into a cellar it was very closed in. It was just, er, I just found it quite unpleasant. It reminded me ... that I'd just sort of gone down into a dark cave. Once you removed the roof, once you got into the corridor it was pretty much the same as the others. ... I don't like small spaces without light, so that probably had an effect on it.' (Student 3)

'I didn't like when we had the roof on, I think it was the M208 one, it was a bit claustrophobic ... and my favourite one was the SchomeBase tree-house, just because it was quite open. The classroom was definitely better with the roof off.' (Student 4)

It is important to add that when the participant was probed further with the question "Are you claustrophobic in real life' the student answered 'Yeah'.

Although the other students were positive about the whole experience, one student was mainly negative, and in particular was more affected by the different environments than the others.

'Where we had the tutorial in the tree-house we kept falling off the platform, and so everything had to stop in the middle of the tutorial to fetch someone back from wherever they'd fallen to. Although entertaining that kind of thing was distracting from the actual tutorial itself. ... I felt the actual surroundings were distracting, and detracted from the lesson considerably. I mean they were very pleasant surroundings. It would have been nice to have been there in person, ...' (Student 2)

It is worth noting that in addition to the students' comments when the tutorial was held in the closed classroom, part way through the students took the decision to move to one of the tree platforms. When the roof was removed from the closed classroom it was possible to move the camera controls and look at the avatars in the classroom from a distance, but apart from that there were no differences in the lighting conditions between the closed and open classroom. This factor makes the claustrophobic reaction even more surprising.

Finally, it is also interesting to note that despite the fact that the students stated there was little difference between the other environments they used very emotive language when describing them. Comments made, which were not recorded, included students comparing the bandstand to places they had attended in the past, or talking about seasons such as being outdoors in the summer. Students' sensory memory that these environments trigger is clearly a starting point for further research.

\section{DISCUSSION \& CONCLUSIONS}

In any social interaction, implicit assumptions are made to assure the interaction's success. If those assumptions are incorrect, we are more likely to misjudge a situation and act inappropriately. Conversely if those assumptions are correct they can increase a sense of being there thus enhance engagement and hopefully attention. For educational purposes it is important to understand what the implications of different environmental design decisions are on student learning.

The findings from this paper highlighted an increased end-user focus in a gaming environment (RuneScape) compared to social world interactions (Second Life). This difference in participant attention is argued could be due to the goal-based nature of the different environments. It could be argued that the differences between the different natures of these worlds could make comparisons difficult. But when the data was investigated to divide tasks within Second Life and RuneScape, the actual differences found weren't large, so may not be statistically significant. This is not surprising considering the small number of participants used in the study. Furthermore the whole definition of immersion, i.e. stating that concentration in the central area implies more attention within a game, might be brought under more consideration. However, the results rely mainly on objective quantitative data, and as a 'proof of concept' demonstrates that using eye tracking hardware can be a valid method of investigating immersion in virtual worlds.

To understand how different social world design issues impact on attention further eye tracking analysis was conducted on the Second Life data. This analysis identified that the Second Life interactions within the 3D world increased participants' focus more than with object and avatar tasks. Ultimately interaction with an environment impacts on our attention thus sense of being there.

Finally different 3D situation designs altered levels of task engagement and distraction through perceptions of comfort, fun and fear. This appears to be a key factor in attention and distraction within an environment but is very much driven by individual differences. This does highlight the growing importance of personalisation in designing for educational purposes. However, this personalisation may be more dramatic that previously envisioned with different types of students requiring different environments. This also highlights the value of virtual worlds as a supplement learning tools not a replacement for other learning environments. 
Virtual environments have the potential to distort the assumptions that guide our behaviour [15]. They also have the potential to increase our sense of attention and sense of place making it more akin to those in face-to-face interactions. While the nature of the environment within a virtual world doesn't have as much effect as in the real world, the finding detailed in this paper clearly show that it can affect learning potential through a genuine 'sense of presence' in virtual worlds. The students' perceptions of 'claustrophobia' within a specific virtual context or the ability to spark memories of old situational experiences highlight an affective level of immersion. We need to understand in more depth how these factors interact with the task being designed for. When designing learning environments we can increase a sense of fun through designing playful situations (e.g. tutorials in a tree). However, an increased sense of attention and immersion that can be felt through these designs can impact on a wide range of affective responses. For example designing a tutorial in a tree could be perceived as fun for many but for some could ignite negative emotive responses due to a fear of heights. The students' attention within this context would turn to distraction. Ultimately when increasing immersion through an improved sense of 'being there' we need to understand the full implications of what that means for different end-users. The question must be posed if these are the basic issues that have hampered virtual worlds for over a decade. Can an online experience be too real for comfort or is it simply a case of understanding how to design these environments appropriately for the task.

\section{ACKNOWLEDGMENTS}

Thanks go to the COLMSCT Centre for Excellence in Teaching and Learning at the Open University, run by Professor Steve Swithenby, for supporting the authors during this work. Special thanks go to the numerous colleagues who have helped and advised us, taken part in the eye tracking pilot study, and been supportive throughout.

The eye tracking work was carried out with the supervision, assistance and technical expertise of Dave Perry, Project Officer (Research and Development) at the Institute of Educational Technology at the Open University, without which the project could not have occurred.

\section{REFERENCES}

[1] Augoustinos, M \& Walker, I. 1995, 'Social Cognition: An integrated introduction' Sage Publications: London

[2] Brna, P. \& Aspin, R. 1997 'Collaboration in a virtual world: support for conceptual learning' In Proceedings of IFIP WG3.3 working conference Dicheva, D. \& Stanchev, I. (eds.) (Human-Computer Interaction and Education Tools) pp. 113-123

[3] Brown, E., Cairns, P. 2004, 'A grounded investigation of immersion in games', ACM Conf. on Human Factors in Computing Systems, CHI 2004, ACM Press, 1297-1300.

[4] Cairns, P., et al. 2006, 'Quantifying the experience of immersion in games', Cognitive Science of Games and
Gameplay workshop at Cognitive Science 2006, Vancouver, July, 2006.

[5] Cheng, K., Cairns, P. 2005, 'Behaviour, realism and immersion in games', ACM Conf. on Human Factors in Computing Systems, CHI 2005, ACM Press, 1272-1275

[6] Delwiche, A., 2006, 'Massively multiplayer online games (MMOs) in the new media classroom', Educational Technology and Society, 9 (3), pp. 160-172.

[7] Fluckiger, F. 1995 'Understanding networked multimedia applications and technology' Prentice Hall, London.

[8] Foster A., 2007, 'Second Life: Second Thoughts and Doubts.', Chronicle of Higher Education [serial online]. September 21, 2007;54(4):A25-A25. Available from: Library, Information Science \& Technology Abstracts, Ipswich, MA. Accessed September 21, 2008.

[9] Harrison, R. \& Dourish, P. 1996, 'Re-Place-ing Space: The Roles of Place and Space in Collaborative Systems.' In Proceedings of the Conference on Computer-Supported Cooperative Work (CSCS'96), ACM Press. pp. 67-76.

[10] Jennett, C. et al. 2008, 'Measuring and defining the experience of immersion in games', Int. J. HumanComputer Studies vol. 66, pp. 641-666.

[11] Kaur, K. 1997, 'Designing Vritual Environments for Usability' in proceedings of Human-Comptuer Interaction. (INTERACT'97) Howard, S. Hammond, J and Lindgaard, G (eds) Chapman \& Hall: Aus pp. 636-639

[12] Kolb, D. A., Rubin, I.M. and Osland, J., 1991, 'Individual and organizational learning', topic introduction, Organizational Behaviour: an experiential approach, New Jersey, Prentice-Hall, pp. 58-60.

[13] Laurel, B. 1993, 'Computers As Theatre'. Addison Wesley. New York.

[14] Oishi, L. 2007, 'Surfing Second Life: what does Second Life have to do with real-life learning? (virtual world)', Technology \& Learning 27.11 (June): 54(1).

[15] Reeves, B. \& Nass, C. 1996 'The media equation: How people treat computes, television and new meida like real people and places.' Cambridge University Press: Cambridge.

[16] Smets, G. J. F., Sappers, P. J., Overbeeke, K. J. \& Van Der Mast, C. 1995 'Designing in virtual reality: perceptionaction coupling and affordances.' In Carr, K. \& England, R. (eds.) 'Simulated and virtual realities elements of perception'. Taylor Francis: London.

[17] Tisdell, E.J., Stohschen, G.I.E., Carver, M.L., Corrigan, P., Nash, J., Nelson, M., Stro-Mackey, R. \& O'Connor, M., 2004. 'Cohort learning online in graduate higher education: Constructing knowledge in cyber community'. Journal of educational technology \& society [1436-4522] vol. 7 iss. 1 pp. $115-127$.

[18] Tromp, J.G., 1995, 'Presence, Telepresence, and Immersion; The Cognitive Factors of Embodiment and Interaction in Virtual Environments'. Proceedings of the FIVE conference, Frameworks for Immersive Virtual Environments, December 18-19, London, UK.

[19] Vygotsky, L. S. 1978, 'Mind in Society: The development of Higher Psychological Processes.' Harvard University Press: Cambridge. 